\title{
PRÁTICA DOCENTE EM EDUCAÇÃO SEXUAL EM UMA ESCOLA PÚBLICA DE JUAZEIRO DO NORTE, CE, BRASIL
}

\section{Teaching practice in sex education in a public school of Juazeiro do Norte, CE, Brazil}

\author{
Glauberto da Silva Quirino ${ }^{1}$ • João Batista Teixeira da Rocha²
}

Resumo: Estudo etnográfico com base na observação participante e entrevista semiestruturada, que objetivou descrever o trabalho de educação sexual dos/as professores/as, e apreender os valores e as atitudes destes/as em relação à sexualidade de adolescentes no espaço escolar. $\mathrm{O}$ trabalho de campo foi desenvolvido em uma escola de Ensino Fundamental e Médio estadual da cidade de Juazeiro do Norte-CE, no período de setembro de 2009 a fevereiro de 2010. Constatou-se que, mesmo sendo o assunto suscitado por parte dos/as estudantes, sempre os/as professores/as se omitiram em realizar qualquer intervenção. Observou-se a presença de valores morais e pessoais na condução das práticas educativas, atitudes de silenciamento em relação ao preconceito a homossexuais e a perda da virgindade, assim como manutenção das desigualdades de gênero. Os dados apontam as fragilidades das ações pedagógicas e a necessidade de mudança de paradigma do processo ensino/aprendizagem.

Palavras-chave: Educação sexual. Sexualidade. Ensino Médio. Ensino Fundamental. Escola pública.

\begin{abstract}
This is an ethnographic study based on participant observation and semi-structured interviews that aimed to describe the teachers' work in sex education and to learn their values and attitudes toward adolescents' sexuality in the school environment. The fieldwork was carried out in a state school for elementary education and high school in Juazeiro do Norte-CE, Brazil, from September 2009 to February 2010. Despite the issue being raised by some students, teachers omitted to perform any intervention. We observed the presence of moral and personal values in the conduct of educational practices, silencing attitudes concerning homosexuality and virginity, and the maintenance of gender inequalities. Data showed the weaknesses of pedagogical action and the need for paradigm changes in the teaching/learning process.
\end{abstract}

Keywords: Sex Education. Sexuality. Basic education. Secondary school. Public education.

\footnotetext{
${ }^{1}$ Universidade Regional do Cariri (URCA), Departamento de Enfermagem, Rua Belo Horizonte, 456, Romeirão, CEP 63030-160, Juazeiro do Norte, CE, Brasil. E-mail: glaubertoce@hotmail.com ${ }^{2}$ Universidade Federal de Santa Maria, Programa de Pós-Graduação em Educação em Ciências: Química da Vida e Saúde, Santa Maria, RS, Brasil.
} 
Quirino, G. S.; Rocha, J. B. T.

\section{Introdução}

$\mathrm{Na}$ década de 1980, cursei $^{3}$ o Ensino Fundamental I, na época, ensino de primeiro grau, em uma escola de base religiosa de denominação evangélica. Lembro-me que, em alguns momentos, de forma periódica, na sala de aula, a professora chamava cada aluno e aluna, individualmente, para dirigir-se até a frente da sala, local em que se encontrava sentada em sua mesa, e inspecionava nossas mãos, cabelos e vestimentas. Nas mãos, observava se as unhas estavam cortadas e limpas; nos cabelos, verificava a limpeza e a presença de parasitas, e, nas roupas, o estado de higiene. Essa inspeção causava-me ansiedade e preocupação diante da possibilidade de encontrar algo em meu corpo ou em minhas roupas que reprovasse minha higidez, pois aquilo me exporia diante dos meus colegas e das minhas colegas, causando-me constrangimento.

Essa atitude da minha professora, na época, estava pautada na Lei n 5.692/71 (BRASIL, 1971), a qual foi regulamentada pelo parecer $n^{\circ} 2.264 / 74$ (BRASIL, 1974), que instituía os Programas de Saúde nas escolas, sobretudo nas séries iniciais do atual Ensino Fundamental I, e tinha como objetivo instruir crianças e adolescentes a adquirirem bons hábitos de saúde. Neste sentido, a saúde era inserida na escola por meio do movimento higienista, com forte componente moral e disciplinar. Nos anos 1990, a nova Lei de Diretrizes e Bases da Educação (LDB) não explicita o ensino da saúde, revogando, dessa forma, a Lei anterior (MEYER, 2006). Entretanto, os Parâmetros Curriculares Nacionais (PCN) (BRASIL, 2000), implementados, ainda, no final da década de 1990, realocavam, como Temas Transversais, as questões da Ética, da Pluralidade Cultural, do Meio Ambiente, da Saúde e da Orientação Sexual, que deveriam ser incorporados nas áreas existentes e no trabalho educativo escolar. Em 2008, a proposta de educação sexual no espaço escolar foi fortalecida por meio do Plano de Desenvolvimento da Educação (PDE) e do Programa de Saúde na Escola (PSE) - este propõe ação articulada da saúde e educação entre os três níveis de governo, para a oferta de ações nas escolas que possibilitem a prevenção da saúde sexual e reprodutiva associada ao debate sobre gênero e orientação sexual, introduzindo o conceito de direitos sexuais e reprodutivos (MANO; GOUVEIA; SCHALL, 2009).

A escola, nesse sentido, configura-se como importante espaço para o desenvolvimento de um programa de educação para a saúde entre crianças e adolescentes. Diferenciando-se das demais instituições por ser aquela que oferta possibilidades de ensino/aprendizagem por meio da construção de conhecimentos oriundos do confronto dos diferentes saberes. Ou seja, a escola precisa estar preparada para apresentar reflexões que possam gerar pensamentos e opiniões críticas entre os/as estudantes, motivando a reflexão sobre o acesso de todos/as à cidadania, respeitando e valorizando a diversidade. Assim, poder-se-á motivar reflexões individuais e coletivas que possam contribuir para a minimização de ações discriminatórias e preconceituosas (BRASIL, 2009).

${ }^{3}$ Realidade experimentada pelo primeiro autor. 
No cotidiano escolar, a sexualidade está presente nas mais variadas formas: nos pressupostos acerca da conformação das famílias, dos papéis e do comportamento de homens e mulheres. Encontra-se no centro de grandes controvérsias contemporâneas que dizem respeito ao futuro das relações sociais de gênero, do casamento, da família, do direito de as pessoas decidirem sobre o corpo e as maneiras de viverem e de exprimirem publicamente as afetividades (CARRARA et al., 2009). É marcada pelo processo de socialização e pelo acesso (ou falta de acesso) à educação, ao diálogo e aos cuidados que a sociedade oferece aos/às jovens. Em termos gerais, isso significa admitir que os indivíduos são socializados para entrada na vida sexual por meio da cultura, que orienta roteiros e comportamentos considerados aceitáveis para cada grupo social (CARRARA et al., 2009).

No contexto da escola pesquisada, em investigação prévia, o conceito de sexualidade foi pensado através dos aspectos biológicos e do direcionamento dos afetos no seu exercício. Apresentou-se com caráter essencialista, e as relações com as concepções de gênero foram expostas de forma subliminar. Secundariamente, havia, em sua constituição, elementos psíquicos, afetivos e espirituais; entretanto, os aspectos históricos e socioculturais foram desconsiderados (QUIRINO; ROCHA, 2012). A partir dessa constatação, considerando que o referencial teórico-conceitual é determinante para atitudes e valores docentes, circundados e determinados pelo contexto sociocultural, que repercute diretamente no processo ensino-aprendizagem, objetivou-se descrever o trabalho de educação sexual dos/as professores/as e apreender os valores e as atitudes destes/as em relação à sexualidade de adolescentes no espaço escolar.

\section{Caminhos da pesquisa}

Este artigo analisa dados de uma pesquisa etnográfica realizada em uma escola pública estadual de Ensino Fundamental e Médio, de Juazeiro do Norte, CE. O trabalho de campo foi desenvolvido entre setembro de 2009 e fevereiro de 2010. A escola tinha 1.485 estudantes matriculados/as, divididos/as nos turnos manhã, tarde e noite, provenientes de, aproximadamente, seis bairros do município, oriundos/as, em sua maioria, das classes sociais mais populares e de famílias com baixo grau de instrução.

Durante o período do trabalho de campo, foram realizadas observações: de aulas nas turmas do $9^{\circ}$ ano do Ensino Fundamental e do $1^{\circ}$ ano do Ensino Médio, de reuniões de professores/as nos intervalos das aulas, e de atividades complementares na sala de multimeios. Foram assistidas as aulas de: Matemática, Física, Português, Artes, Química, Educação Física, Biologia, Filosofia, Sociologia e Geografia.

Além das observações, foram realizadas sete entrevistas semiestruturadas com os/as professores/as que tiveram suas aulas observadas - para tanto, foi utilizado gravador de áudio, sendo as mesmas realizadas na escola, em sala reservada e de forma individual. As entrevistas realizadas tiveram como objetivo ouvir as explicações para o fenômeno estudado, fornecidas pelas/os "nativas/os" (NAKAMURA, 2009). Para manter o sigilo e a confidencialidade da identidade dos/as entrevistados/as, os nomes dos/as sujeitos/as são fictícios.

Participaram da pesquisa quatro professoras e três professores, a média de idade foi de 37,7 anos, com variação de trinta a 45 anos. Quanto à religião, todos/as se declararam católicos/as. Em relação ao estado civil, três estavam solteiros/as, três casados/as e um/a 
Quirino, G. S.; Rocha, J. B. T.

divorciado/a. E, quanto à formação acadêmica, todos/as se graduaram em Instituições de Ensino Superior públicas, sendo que apenas um/a docente não tinha pós-graduação lato sensu.

Quando interrogados sobre os aspectos do trabalho docente, seis professores/as tinham carga horária semanal de quarenta horas/aula e apenas um/a de vinte horas/aula, quatro possuíam contrato temporário e três faziam parte do quadro efetivo da escola. O tempo de atividade na escola variou de um a oito anos, sendo que quatro professores/as trabalhavam em outra unidade escolar do município, e os demais apenas na unidade pesquisada, entretanto, nenhum/a possuía atividade laboral em escola de caráter privado, sendo todos/as funcionários/as públicos/as. Em geral, ministravam mais de uma disciplina alinhada à área de formação acadêmica.

\section{O trabalho pedagógico de educação sexual}

Em pesquisa anterior com o mesmo grupo de professores/as, que objetivava conhecer a percepção sobre sexualidade e educação sexual desses/as docentes, constatamos que eles/elas entendiam a educação sexual como: um processo de orientação, no qual ocorreria a preparação dos/as jovens para a relação sexual, prevenção das doenças sexualmente transmissíveis e gravidez, descrição da fisiologia e desenvolvimento corporal, e conhecimento das relações sociais que modulam os papéis de gênero e da orientação sexual. Esta deve ser iniciada no quarto ou quinto ano do Ensino Fundamental, sendo as aulas de ciências o espaço privilegiado para se realizar tal orientação (QUIRINO; ROCHA, 2012).

Durante as entrevistas realizadas com o corpo docente, foi prevalente a assertiva de que o trabalho de educação sexual com os/as jovens adolescentes ocorria em contextos específicos, a partir das demandas do grupo que eram externadas por meio de perguntas, de dúvidas e do comportamento deles/as. Destacaram que nem sempre o tema era suscitado de forma explícita, podendo apresentar-se por meio de piada ou brincadeira, na qual estava implícita a sexualidade. Entretanto, isso exigia observação e esperteza por parte dos/as professores/as para perceber essa necessidade, o que fazia com que poucos/as trabalhassem essas questões. Apontaram como causas da parca atuação docente sobre a educação sexual: a pouca sensibilidade para essa percepção, o despreparo teórico-conceitual sobre a temática, a dinâmica do trabalho pedagógico que privilegia conteúdos formais, e o desinteresse dos/as professores/as em discutir com os/as adolescentes aspectos voltados para a sexualidade.

O trabalho de educação sexual deveria ser desenvolvido de forma grupal, pois, na percepção docente, os aspectos relativos à sexualidade não deveriam ser tratados de forma individual, entretanto seria importante que fosse de uma maneira sutil. Havia quem defendesse a manutenção do tema de forma transversal, e existia quem acreditava que deveria haver disciplina específica, pois, em geral, os/as adolescentes necessitavam de informações mais frequentes - estas diminuiriam a necessidade de se falar de sexo e 'naturalizariam' o assunto. Ademais, foram frequentes as sugestões de trabalho a partir de projetos anuais sobre sexualidade que envolvessem toda a comunidade escolar, os quais teriam a vantagem de lembrar o/a professor/a da prerrogativa de desenvolver uma educação voltada à vida sexual dos/as discentes, que, a cada ano, se renova em seus/suas agentes e conteúdos. 
Geralmente, atribuímos as marcas da escola sobre o processo educativo aos conteúdos programáticos, entretanto mais profundas e permanentes na nossa constituição enquanto sujeitas/os são aquelas provenientes: das situações do dia a dia, das experiências comuns ou extraordinárias que vivemos em seu interior, a partir da interação com colegas, professores/as e funcionárias/os (LOURO, 2010).

Essa aparente sutileza educativa parece não estar articulada à discussão das questões sociais, éticas, históricas, culturais e políticas - princípios fundamentais em um trabalho de educação sexual que deve estar pautado na liberdade, autonomia e no respeito à intimidade das/os sujeitas/os (CAMARGO; RIBEIRO, 2010). Isso significa dizer que não é possível permanecer subsidiada por valores, estritamente, pessoais. Ainda, conforme as autoras citadas, esse trabalho deve ser realizado no intuito de permitir a participação e os questionamentos constantes das/os envolvidas/os no processo, por meio de discussões que permitam cada sujeito/a se posicionar, o levantamento e discussão das dúvidas, das divergências e dos pontos convergentes. Essa atitude promove posição mais crítica, favorecendo a reflexão dos fatos que podem influenciar a vida sexual em seu contexto sociocultural, facilitando as relações interpessoais. Por isso, a importância do componente transversal, pois facilita a construção da cidadania em termos éticos e políticos, uma vez que implica o compromisso dos princípios: do respeito, da solidariedade, responsabilidade, liberdade, autonomia e dos direitos e deveres da vida cidadã.

Ressalta-se que, ainda, encontramos a associação da educação sexual com as aulas de Ciências. Quando fizemos o primeiro contato com os/as integrantes da escola, conversamos inicialmente, com um/a professor/a do núcleo gestor, ao expor o objeto da pesquisa; ele/a se mostrou solícito/a, concordando com a viabilidade da pesquisa, e sugeriu que observássemos as aulas de Biologia. Essa ideia foi reiterada ao se constatar que, na sala de multimeios, os livros relacionados ao tema sexualidade estavam incluídos juntos aos de Biologia. O que faz com que as disciplinas das chamadas Ciências da Natureza encontrem legitimidade na produção de um discurso reconhecido como verdade? Essa resposta pode ser encontrada a partir do Iluminismo, cujo paradigma científico lançaria uma luz sobre a mente humana que se encontrava nas trevas. Vale a pena, nesse sentido, resgatar o conceito de saber dominado por Foucault (2009a), que refere a uma série de saberes que tinham sido desqualificados como não competentes ou insuficientemente elaborados: saberes ingênuos, hierarquicamente inferiores, saberes abaixo do nível requerido de conhecimento ou de cientificidade. Não é de forma alguma um saber comum, um bom senso, mas, ao contrário, um saber particular, regional, local, um saber diferencial, incapaz de unanimidade, e que somente deve sua força à dimensão que o opõe a todos aqueles que o circundam.

Em relação às estratégias pedagógicas que os/as professores/as utilizavam para abordar a educação sexual, destacaram-se as aulas expositivas com uso de: textos dos livros didáticos, vídeos, palestras, filmes, notícias jornalísticas, debates em sala de aula e pesquisa escolar. $O$ diálogo e a conversa visavam à sensibilização e conscientização dos/as estudantes. Foram destacados, como temas relevantes para o trabalho de educação sexual: a gravidez na adolescência, as doenças sexualmente transmissíveis, a virgindade, o ato sexual, a homossexualidade, e os métodos contraceptivos - estes incluíam: a tabela, a camisinha e a pílula. 
A racionalidade foi um aspecto valorizado pelos/as professores ao se tratar de temas que envolviam a sexualidade adolescente, isso implicava o uso do saber e da consciência, que estaria em oposição à popularidade e banalização do sexo. Os valores tradicionais ${ }^{4}$ apareceram nesse momento e o discurso centrava-se na prevenção, permeada pela ideia de higidez física, social e moral, pois visava à formatação ou adequação dos comportamentos dos/as estudantes a um determinado padrão, usualmente, fixo, de recato, passividade e vertical. Nesta perspectiva, os homossexuais foram apontados como a categoria desviante do padrão, chegandose a afirmar "que não é o fato da opção da sexualidade que você tem que ter um comportamento diferenciado, seu comportamento tem que ser adequado" (prof. Eduardo). No entanto, todo o processo didáticopedagógico da educação sexual, ainda, estava voltado para atitudes e valores de ordem pessoal e moral: "eu introduro o que eu sei, o que eu aprendi, o que eu acho certo" (profa. Regina). Em certas ocasiões, chegava-se a avaliar a orientação sexual pelos estereótipos: "Eu observo muito o comportamento deles [...] se tem homossexualismo, se só tem heterossexualismo (sic)” (prof. Eduardo).

Em contrapartida, os discursos não se alinharam às atitudes observadas durante o trabalho de campo em sala de aula. O que se constatou foi, mesmo sendo o assunto suscitado por parte dos/as estudantes, os/as professores/as se omitiram em realizar intervenção conceitual ou pedagógica. Quando, em algum momento, o conteúdo trabalhado no material didático, em forma de apostila, fornecido pelo Governo do Estado do Ceará, permitia a introdução ou discussão mais aprofundada do assunto, esta era realizada de forma superficial e permeada de valores morais e pessoais. Essa atitude de pouco problematizar e silenciar-se quanto aos assuntos sexuais pode ser considerada paradoxal na sociedade brasileira, marcada por manifestações da sexualidade, expostas por meio de piadas, gracejos, em fotos de capas de revistas, nas danças dos programas televisivos, nas imagens comerciais ou na rede cibernética. Outra consequência promovida é o aprendizado do silêncio, especialmente, sobre assuntos considerados tabus, como: a masturbação, a virgindade, a relação sexual e a homossexualidade (RAGO, 2010).

Durante uma aula de Português, foi trabalhado um texto intitulado "De volta ao grunhido", de Luís Fernando Veríssimo (1997), o qual enfatizava o uso da internet em substituição ao contato físico nos relacionamentos afetivos, como o namoro. Tinha um tom nostálgico, relembrando a época em que o namoro, para acontecer, demandava tempo e contato pessoal. Comparava o namoro virtual ao período do homem da caverna, em que o macho emitia um grunhido e levava a fêmea, sendo que, hoje, o grunhido era virtual. Comentava que as pessoas acreditavam em uma revolução sexual, entretanto, na opinião do autor, o que ocorreu foi o fechamento de um ciclo, uma involução. Concluía que, em um futuro breve, a linguagem oral seria perdida e substituída pelo uso da internet. $\mathrm{O} / \mathrm{A}$ professor/a, que ministrava a aula, comentou que o texto era divertido e se limitou à descrição textual. Uma aluna e um aluno discutiam devido à ideia de que as mulheres estariam mais liberais; a aluna discordou e disse que elas "têm atitude" e os homens não. O/A professor/a perguntou quem já tinha namo-

\footnotetext{
${ }^{4}$ Por valor tradicional considera-se a descrição 'nativa' que corresponde ao envolvimento sexual baseado em um sentimento relacional de amor entre os/as parceiros/as; nele exige-se pudor e perda da vulgaridade, sendo que o intercurso sexual acontece dentro de um contexto de relacionamento estável.
} 
rado pela internet; apenas dois alunos confirmaram ter namorado, no entanto, não sabíamos quantos tinham acesso à internet. Relatou o caso de uma amiga que sofreu uma decepção amorosa devido a um namoro virtual. A/O professor/a não conseguiu aprofundar o debate $\mathrm{e}$ trabalhar criticamente os conceitos e valores embutidos no texto, inclusive; não fez reflexões sobre a construção literária e as discussões surgidas durante a aula.

Outro fato que mereceu atenção foi a distribuição espacial da sala de aula, que obedecia ao gênero, com raras exceções: as meninas estavam, exclusivamente, na primeira metade da sala, e os meninos se encontravam, predominantemente, na segunda metade da sala em direção ao fundo. Isso aconteceu em decorrência do mapeamento ${ }^{5}$ da turma, que objetivava diminuir a desordem e a indisciplina em sala de aula, executado pela Coordenação Pedagógica da escola. Quando o/a professor/a começava a reordená-los/as a partir desse mapa, alguns/as se realocavam espontaneamente. Diante disso, uma aluna questionou essa posição autoritária da equipe diretiva. Essa divisão sexual do espaço didático parece relacionar-se ao estereótipo de gênero que associa a performance feminina ao interesse, bom comportamento, recato e dedicação. Nesta perspectiva, a segregação visava a não- contaminação das meninas pela indisciplina masculina, o que transformava a sala de aula em uma arena sexista, referendando ou ampliando as desigualdades das relações generificadas.

A sala de aula era um ambiente no qual havia sempre muito barulho no início de cada aula; este tendia a diminuir no seu transcorrer, entretanto, chegava-se a perder 40 minutos para que a ordem e o silêncio se estabelecessem. A estratégia dos/as estudantes parecia ser proposital para que a concentração e a atenção fossem perdidas, pela dificuldade que apresentavam para concentrar-se no conteúdo ministrado ou, ainda, pela presença de um observador externo. A estratégia pedagógica e o material didático utilizados eram, exclusivamente: aula expositiva, leitura textual da apostila, resolução oral das perguntas do caderno de atividades, uso do quadro-negro e giz ou quadro-branco e pincel. A maioria dos/as professores/as verificava a presença dos/as estudantes, chamando-os/as pelo número do diário de classe. Essa limitada diversificação de recursos e estratégias didáticas talvez estivesse relacionada às condições de trabalho adversas - como estrutura de sala de aula, percepção salarial, jornada de trabalho, e colaboração dos/as estudantes - que, uma vez associadas aos aspectos da formação acadêmica e continuada, perpassadas pela subjetividade individual, promovessem, no corpo docente, a desmotivação necessária para não implementar estratégias didáticas mais atraentes.

As práticas pedagógicas se pautavam, estritamente, no ensino, o que dividia os papéis entre quem ensinava e quem aprendia. Neste processo, a eficácia do sistema era medida pelo ritmo apresentado no avanço progressivo da sequência de conteúdos, sendo cumulativo e linear. Os objetivos comportamentais são usados para medir o sucesso de cada etapa e produzem categorias que resultam em punições e recompensas (CAMARGO; RIBEIRO, 2010). Isso pode ser exemplificado ao serem observadas as ameaças de rebaixamento de notas, se os/ as adolescentes não tivessem um comportamento caracterizado como aceitável; ou ainda, quando as atividades no caderno de exercício eram requeridas para o/a professor/a "dar um visto", e se

${ }^{5}$ Havia, nesse sentido, um mapa que indicava onde cada aluno/a deveria sentar-se, daí o nome mapeamento. 
Quirino, G. S.; Rocha, J. B. T.

os/as estudantes não tivessem com essa atividade finalizada, podiam ser penalizados/as com a diminuição da nota na avaliação escrita. Entretanto, parte considerável das perguntas exigia discussão das possibilidades possíveis de resposta, fato que, em geral, não se concretizava e a atividade era, literalmente, vista pelo/a docente.

\section{O "viado"}

Em vários momentos, os meninos utilizavam o termo "viado" para se referir a outro menino, em geral, isso acontecia em um contexto de xingamento. Em uma aula de Matemática, um aluno fez uma pergunta sobre uma dúvida relacionada ao conteúdo trabalhado em sala. Diante dessa situação, outro estudante falou em voz alta: "Deixa de ser burro, seu viado!". Havia outro adolescente sentado no meio das meninas, este fez algum comentário sobre o que foi dito e outro aluno sentado entre os meninos respondeu: "Tá revoltado? Terminou com o namorado!”. Situação semelhante foi encontrada por Souza (2006) ao constatar que, quando um menino não correspondia às expectativas associadas aos homens, este era estigmatizado, marginalizado e classificado como "gay", "bicha" e "veado". O/A professor/a se manteve calado/a, continuando as atividades letivas e não teceu nenhum comentário sobre o fato ocorrido na sala de aula.

O silenciamento e a negação são apontados por Louro (2010) como estratégias escolares para o incentivo e contenção da sexualidade 'normal', pois a heterossexualidade deve ser estimulada, entretanto a sexualidade deverá ser adiada para a vida adulta. Portanto, àqueles e àquelas que expressam de forma mais evidente, em seus corpos, sua sexualidade, e que percebem interesses ou desejos distintos da heteronormatividade, restam poucas alternativas, como: o silêncio, a dissimulação ou a segregação - essa rejeita a homossexualidade e se expressa por uma declarada homofobia, que limita a expressão da intimidade entre homens e os conduz a empregarem apenas gestos e comportamentos autorizados para o 'macho'.

O "viado" foi caracterizado como aquele que tem um estereótipo diferente da performance social de gênero esperada para o homem, portanto são indivíduos afeminados e pouco masculinos. Este fala e ri demais, usa trejeitos e maquiagem femininos, seu comportamento é extravagante e irreverente. Aproxima-se do gênero feminino, porém as mulheres jamais teriam um comportamento semelhante. Os/As docentes acreditam que eles não têm necessidade de comportar-se assim, pois deveriam manter-se recatados, entretanto os usos dos trejeitos e de expressões corporais são estratégias de enfrentamento do preconceito, pois são pessoas reprimidas, que guardam traumas em relação à orientação sexual e que, quando conseguem a libertação dessas amarras da subjetividade, se soltam, liberam ações e, consequentemente, extravasam. Agindo, assim, conseguem se impor e ganham visibilidade social. Nota-se, nessa descrição, que a homossexualidade está necessariamente associada a algum desvio da normalidade, de ordem psíquica ou emocional; dessa forma, não há necessidade de questionar a origem da heterossexualidade, pois esta faz parte da 'natureza' humana, portanto 'normal' e imutável.

${ }^{6}$ Sinonímia utilizada pelos/as atores e atrizes sociais da pesquisa: boiola, gay, homossexual e bichona. 
O alvo das agressões era sempre João, um adolescente que se sentava na segunda fila da frente, único menino que se localizava no meio das meninas, pouco falava em sala de aula e, geralmente, interagia mais com as meninas do que com os meninos; aos olhos dos colegas, apresentava uma performance de gênero mais feminina e, por isso, era o centro das brincadeiras, gozações e xingamentos. Em outra ocasião, João saiu da sala chorando após uma colega falar-lhe algo no ouvido. Os alunos começaram a fazer comentários em tom irônico e depreciativo: "Ele terminou com o namorado!"; "O namorado morreu"; "Ele é gay!”. Essas afirmações objetivavam dizer que o fato de João demonstrar sensibilidade, sentimento associado à subjetividade feminina, não necessitava de nenhuma preocupação, pois isso fazia parte da 'essência' dele, dessa forma, seria dispensável qualquer intervenção.

Os comentários dessa natureza sobre a homossexualidade masculina não eram exclusividade dos adolescentes ${ }^{7}$. Na sala dos/as professores/as, Renata estava fazendo o levantamento do tamanho das blusas desejadas pelos/as docentes e considerou-se a possibilidade de Marcelo usar uma "baby look." Este afirmou que não teria corpo para isso; Flávia comentou que daria certo o professor Conrado usar, uma vez que ele era forte. A professora Regina afirmou que ele ficaria parecido com o Vicente, aluno do terceiro ano. Os/as professores/as riram e o professor Marcelo perguntou quem era o estudante citado. Outro docente respondeu: "É uma bichona!". A professora Vitória comentou que encontrou Vicente colocando lentes de contato e observou que ele é muito "afetado", gesticula com muita intensidade as mãos. Ocorreram risos e comentários gerais, ao mesmo tempo que ficou impossível compreender o que estavam dizendo.

Desde muito cedo, meninos e meninas aprendem piadas, gozações, apelidos e gestos para se dirigirem àqueles/as que não se ajustam aos padrões de gênero e de sexualidade admitidos na cultura que estão inseridos/as. Dessa forma, a homofobia é consentida e ensinada na escola, e se expressa pelo afastamento, pelo desprezo ou pela imposição do ridículo; portanto, em raras exceções, o homossexual admitido é aquele que disfarça sua condição, pois, como a sexualidade, do ponto de vista liberal, é uma questão privada, deve ser mantida em segredo e vivenciada apenas na intimidade. A partir desta perspectiva, pode-se compreender que o que realmente incomoda é a manifestação aberta e pública de sujeitos e práticas não heterossexuais. Logo, a escola é um dos espaços mais difíceis de alguém assumir uma identidade homossexual, pois, ao negar e ignorar a homossexualidade, legitima determinadas identidade e prática sexuais, enquanto reprime e marginaliza outras (LOURO, 2010).

Mesmo ocorrendo comentários jocosos sobre a orientação sexual dos meninos, os/as professores/as concordaram que o uso do termo "viado" era pejorativo e caracterizava-se como uma agressão, causada pelo preconceito. Entretanto, houve quem considerasse que o uso da palavra tinha perdido a conotação de xingamento, uma vez que seu uso já era tão corriqueiro e habitual entre os adolescentes, que tinha adquirido o status de brincadeira, o que não causaria mais espanto, admiração e escândalo por parte de quem o escuta. Na primeira

${ }^{7}$ Não foi observada a utilização do termo "viado" pelas meninas adolescentes.

${ }^{8}$ Criação brasileira para traje - especialmente camiseta - justo/apertado, dando impressão de ser roupa infantil (SANTOS, 2006). 
situação, exigia intervenção docente no sentido de conscientizar os/as estudantes para a obrigação de respeitar a "opção sexual" do outro, mesmo observando que este outro é diferente e que a preferência sexual é um aspecto da vida privada. Quanto ao segundo entendimento, este permitiria a neutralidade dos/as professores/as, dessa forma, não necessitaria de nenhuma intervenção. Vale a pena ressaltar que foi indicado cuidado no momento de intervir, pois, em um primeiro instante, corria-se o risco de reafirmar ainda mais aquela ideia ao sair em defesa do que foi atingido, uma vez que se poderia pensar que ele era tão frágil que o/a professor/a precisou defender.

Como o tema homossexualidade era recorrente e nele centravam-se os principais problemas percebidos durante a observação em sala de aula, solicitamos que os/as professores/as indicassem a melhor forma de se trabalhar com esse grupo no espaço escolar, se existia preconceito e onde este se localizava. A maioria concordou que os homossexuais deveriam ser tratados sem distinção, procurando vê-los com naturalidade, como um ser humano normal, e que não deveria haver diferenças no ato de lecionar. Era fundamental discorrer sobre o assunto, pois isso diminuiria o tabu associado. Entretanto, esse trabalho era considerado difícil pela presença do preconceito, por ser uma minoria e pelo processo de exclusão no qual estavam submetidos.

Ao retratarem o preconceito, afirmaram que este ainda era muito grande e localizavase, sobretudo, entre os/as estudantes. Mas, foram indicadas como fontes de preconceito: a sociedade, as pessoas mais velhas e a família. Observou-se que era difícil admitirem a existência de formas preconceituosas de pensar e agir contra homossexuais entre os/as professores/ as, que, em geral, assumiam atitude mais polida ao falar do "grupinho", chegando a afirmar que seria um absurdo um/a docente ter esse tipo de conduta; caracterizaram essas atitudes como brincadeiras e diversão, e apenas a professora Simone reconheceu que não sabia dizer se era um tipo de diversão "saudável"; o professor Conrado foi mais enfático e assegurou que existia preconceito entre os/as professores/as. Embora, a professora Thaís acreditasse que a "mente dos professores está mais aberta", relatou um caso que considerou grave e classificouo como homofobia: um professor pediu, à direção da escola, para ser transferido de uma sala porque tinha "viado" demais para ele dar aula e não tolerava aluno "viado".

Conversas, exemplos e piadas são construídos a partir da prerrogativa de que todos/ as na escola e na sala de aula são heterossexuais. Rapidamente, a noção valoral de que todos/ as necessitam ser heterossexuais é estabelecida e acompanhada da ideia de que ser diferente é anormal ou errado (MOSCHETA; MCNAMEE; SANTOS, 2011). Para Borges et al. (2011), as discriminações homofóbicas podem ocorrer de forma simétrica, quando acontecem entre alunos/as e jovens da mesma idade ou ano escolar; e/ou assimétrica, ao vir de brincadeiras, risos, silêncios ou, mesmo, da indiferença dos/as professores/as e funcionários/as da instituição que deveriam educá-los/as e protegê-los/as. Esse comportamento reflete a sociedade de forma mais ampla, construída a partir do preconceito às diferenças, e promove, nas vítimas, sentimento de não-pertencimento ao grupo hegemônico heterossexual, o que culmina na sensação de desconforto, intimidação e exclusão diante dos/as demais.

Diante dessas circunstâncias, os/as professores/as reconheceram que necessitavam de melhores informações para conseguirem lidar com essas situações; acrescentaram que a orientação deveria ser extensiva para os/as estudantes, na perspectiva de que os homossexuais "consigam se entender" e, assim, serem felizes com sua "condição". Isso poderia acontecer 
por meio de oficinas e capacitações voltadas para sensibilização dessas questões. Entretanto, o que se observou foi um silêncio generalizado dos/as docentes; essa atitude pode ser decorrente: do uso habitual do termo, que promoveu um processo de dessensibilização, da falta de referencial teórico-conceitual que permita abordar a temática, ou, ainda, da legitimação da agressão, referendando o preconceito.

Podemos afirmar que a posição ou a atitude dos/as professores em relação à homossexualidade se alternava entre a abordagem absolutista e a liberal. A abordagem absolutista é uma posição moral que prevê um controle autoritário e rígido; nela a moralidade está inscrita em instituições sociais, como o casamento, a heterossexualidade, a vida familiar e a monogamia, tendo suas raízes na tradição religiosa judaico-cristã; a abordagem liberal é uma posição que ainda não está convicta de que o sexo é bom ou ruim, entretanto, está convencida das desvantagens, tanto do autoritarismo moral quanto do excesso, ela direciona as iniciativas do Estado e a formulação das leis (WEEKS, 2010).

\section{"Não há mais moças"}

$\mathrm{Na}$ aula da professora Thaís, havia muito barulho, mesmo assim, ela o ignorou e continuou lendo o texto da apostila. Uma senhora entrou em sala para avisar sobre o preço do fardamento escolar. Os/As estudantes entenderam que, na blusa, haveria a logomarca da empresa de confecção, o que gerou um tumulto. Havia muitos gritos na sala, a professora ameaçou diminuir a nota da avaliação. Haveria apresentação de Biologia, do grupo teatral do Colégio Liceu no pátio da escola, mas a turma foi impedida de participar por medida disciplinar. Thaís reclamou que aquele não era comportamento de rapazes e moças. Um aluno ao ouvir essa afirmação, disse que "não há mais moça". Uma aluna sentiu-se ofendida com a assertiva e falou que ela não era igual às meninas que ele pegava. A professora se manteve em silêncio e a discussão entre os/as estudantes sobre comportamento adequado prosseguiu.

$\mathrm{Na}$ opinião dos/as entrevistados/as, isso reflete o avanço da modernidade, que facilitou a chegada precoce da informação e da "liberação da sexualidade", fazendo com que as meninas perdessem a virgindade mais cedo, fato evidenciado pelo intercurso sexual no início de um relacionamento afetivo. Nesse aspecto, a mídia televisiva tinha papel fundamental nessa difusão de ideias e valores. Os/as docentes manifestaram a necessidade de conversar com os/ as adolescentes, na tentativa de desmistificar a sexarca e aumentar a informação, para que isso não culminasse em uma gravidez e esta viesse a interromper a trajetória escolar, o que diminuiria as chances de mobilidade social e entrada no mercado de trabalho.

O fenômeno da gravidez na adolescência não é novo no cenário brasileiro, e abriga uma faixa etária que já foi considerada como ideal para se engravidar. Ela deve ser entendida a partir da transição demográfica brasileira. Dessa forma, é fundamental considerar alguns aspectos: entre 1970 e 1991, houve pouca variação nas taxas de fecundidade entre as mulheres de 15 a 19 anos e, entre 1965 e 1995, a fecundidade da população em geral caiu de quase seis crianças/mulher para um pouco mais de duas; portanto, pode-se inferir que ocorreu decrésci-

\footnotetext{
${ }^{9}$ Quando uma garota perde a virgindade, diz-se que ela não é mais moça.
} 
mo das taxas entre mulheres maiores de 20 anos e estabilidade delas nas adolescentes, o que gerou aumento da visibilidade e mudanças no papel social das mulheres com acesso à escolarização, inserção profissional no mercado de trabalho e desvinculação da sexualidade, e reprodução por meio do aumento do uso de métodos contraceptivos. Assim, engravidar na adolescência seria um desperdício de oportunidades, como se as oportunidades sociais fossem iguais para todas as classes. A ideia é reforçada pelo senso comum e pela mídia, que consideram o abandono escolar, e a consequente inserção precária no mercado de trabalho, como uma situação que instaura ou agrava a marginalidade social e econômica. No entanto, o que foi constatado por meio de pesquisa multicêntrica, aqui no Brasil, é que existe um caráter indissociável na articulação entre classe social e gênero na compreensão do fenômeno, pois, nas classes médias e nas populares, a paternidade impacta pouco nos percursos escolares e profissionais dos adolescentes, sendo que, nos estratos médios, há preservação de projetos e percursos educacionais, e, nos estratos populares, as inflexões mais significativas são decorrentes de fatores sociais e econômicos que antecedem a paternidade; o impacto gerado pela maternidade nas classes médias acontece na limitação do lazer e convívio social, assim como na interrupção temporária da trajetória escolar, sendo que, depois da primeira gravidez, as jovens passam a se prevenir e tendem a exigir o uso do preservativo masculino - nesse aspecto, parece ser um evento episódico, justificado pelas expectativas da carreira profissional; entretanto, nas classes populares, a maternidade tem impacto mais significativo, pois as restrições são bem mais proeminentes, assim: as carreiras escolares têm caráter mais errático, há dificuldade de conciliar os estudos com o trabalho e essas atividades com as responsabilidades maternas e domésticas, o que complica ou impossibilita a vida escolar, que é agravada pela reincidência gestacional, pois a experiência da maternidade não impõe, necessariamente, mudanças nas trajetórias anticoncepcionais (HEILBORN et al., 2002).

Paradoxalmente, a virgindade, atualmente, não é considerada valor social importante, pois não está mais atrelada ao casamento; no entanto, a banalização, na qual o sexo está submetido e a "cultura tradicional" 10 , faz com que as meninas, ao manterem uma vida sexual ativa, tornem-se mais "banais" e, portanto, perdem o valor. Passam a ser desvalorizadas, uma vez que os meninos as querem "só para curtir", pois ainda esperam que estejam guardadas, para eles, uma "mocinha virgem". As/Os docentes acreditam que o início da atividade sexual somente devia acontecer em um contexto de responsabilidade e informação, para não ocorrer a gravidez e as doenças sexualmente transmissíveis.

Embora a manutenção da virgindade feminina não tenha sido apontada como aspecto importante na atualidade, observamos que ainda é considerada fundamental para valorar e classificar a mulher. Discorrendo sobre isso, Furlani (2003) afirma que algumas práticas sexuais têm sido apontadas como mito e tabu ${ }^{11}$, pois, da mesma forma que recebem uma carga

\footnotetext{
${ }^{10} \mathrm{O}$ sentido de cultura tradicional aqui se refere ao machismo e patriarcalismo.

${ }^{11}$ Mito: do grego, mithus, significa fábula; o mito sexual é uma concepção errônea criada a partir de rumores, superstições, fanatismo ou educação sexual falha. Tabu: do polinésio, significa sagrado ou invulnerável; os tabus sexuais são atos, palavras ou símbolos sexuais proibidos em uma determinada sociedade por motivo religioso ou social (FURLANI, 2003).
} 
de informações estereotipadas, associam forte preconceito e discriminação social. Dentre essas práticas, é apontada a virgindade feminina. Esta, enquanto tabu, configura-se como o alicerce das sociedades ocidentais no sentido de virtude e uma das formas mais terríveis de subordinação e machismo em nossa cultura, mantendo estreita relação com os dogmas cristãos. Este mito está na formação da repressão sexual na sociedade patriarcal, na dominação machista e na desigualdade de gênero, pois, em um contexto em que virgindade e castidade são sinônimos de sublime virtude, sexualidade seria sinônimo de impureza e pecado. Como mito, a ideia fundamental está centrada na crença de que ser virgem significa ser virtuosa e ter qualidade moral. A virtude seria condição associada a sua perda dentro do casamento, ou nos dias atuais, dentro de uma relação afetiva estável, com parceiro único, o que conferiria à mulher todo o respeito.

O casamento, ainda, foi citado pela professora Regina como o sonho de muitas meninas. Tabet (1985) considera que a instituição do casamento é uma estratégia ligada à exploração sexual do trabalho que tem como objetivo subordinar a mulher em ciclos ininterruptos de gravidez-aleitamento por meio de mecanismos que promovem o controle da função reprodutiva feminina, transformando uma potencialidade biológica em uma reprodução forçada. Para a autora, a espécie humana é relativamente infértil, pois há apenas $25 \%$ de chances de uma mulher engravidar em uma única relação sexual; o intercurso sexual acontece independentemente da ovulação, o impulso sexual é intermitente e não está ligado à procriação, sendo que não ocorre sinalização do momento da fertilidade, como no ciclo estral dos animais. Dito isso, como fazer então, com que as mulheres reproduzam? A resposta é simples: aumentando a exposição e a frequência ao coito por meio das relações matrimoniais. O casamento é marcado pelo adestramento e aprendizagem da mulher ao coito; por meio de estratégias de violência e força, os homens legitimam a submissão feminina à vontade sexual do marido, criando condições de obtenção máxima da fertilidade, e a gravidez, por sua vez, aparece como o melhor meio de mantê-las no casamento. Isso significa que o casamento culmina na imobilização das mulheres para fazê-las gerar, e fecundá-las para imobilizá-las. Portanto, a reprodução, nessa perspectiva, não se constitui um fato biológico, mas, acima de tudo, um sistema de controle e de manipulação do corpo feminino, pois as diferentes intervenções sobre a sexualidade visam a produzir um organismo feminino especializado na reprodução.

\section{"Falar demais em sexo"}

O sexo está na ordem dos discursos. Os/as professores/as, durante o intervalo, comentaram que uma aluna do segundo ano pensava e falava em sexo demasiadamente, e que ela deveria fazer psicanálise, pois o problema dela não se resolvia na escola; ao sair, um professor comentou que um aluno disse sobre uma estagiária do curso de educação física: "essa professora é boa mesmo, eu vou comer"12!". O professor riu e comentou que achava que ela tinha escutado. Nesta situação, constatamos as diferenças no âmbito sexual das hierarquias de gêne-

${ }^{12}$ Geralmente, o homem usa esse termo no sentido de ter relações sexuais com outra pessoa. 
ro. Quando uma menina tem esse tipo de atitude, ela é considerada patológica e, portanto, passível de tratamento e cura, mas, quando é um menino, esse comportamento é esperado e até estimulado, pois faz parte da "natureza" masculina. Constata-se, nesta perspectiva, que o discurso e o ato sexual são marcados pela desigualdade de gênero, e faz parte da base estruturante da subjetividade dos/as sujeitos/as na sociedade brasileira, especialmente, no nordeste brasileiro, em que há o costume de dizer: "prendam suas cabras porque o meu bode está solto".

Esse aspecto proscritivo do sexo para as mulheres tem suas bases históricas a partir da separação da relação sexo/prazer - com o intercurso sexual tendo fins apenas procriativo , realçada pela era Vitoriana, nas políticas higienistas implementadas, no Brasil, nas últimas décadas do século XIX e na sociedade burguesa. O espaço familiar e escolar é transformado em ambiente de formação dos/as filhos/as por meio do controle dos seus corpos e de uma educação do sexo, que indicava o que deveria ser dito, quem falava e onde se falava (CAMARGO; RIBEIRO, 2010). Para Foucault (2009b), a repressão sexual é marcante na sociedade ocidental, entretanto, os mesmos mecanismos que proíbem o falar em sexo são utilizados para a incitação ao discurso no sentido de institucionalizá-lo e controlá-lo. Essa foi, portanto, a forma que se encontrou de vigiar, normatizar e controlar a sexualidade, sendo a confissão a estratégia usada para o isso, pois através do adestramento corporal, da ampliação de suas aptidões, da extorsão de suas forças, do crescimento paralelo de sua utilidade e docilidade, da sua integração em sistemas de controle eficazes e econômicos que o poder disciplinar atua sobre os corpos e nas sexualidades.

$\mathrm{Na}$ ocasião das entrevistas, perguntamos a opinião dos/as professores/as sobre um/ a estudante falar constantemente em sexo. A maioria acreditava que, quando isso ocorria, era porque aquela pessoa tinha alguma dúvida, faltavam informações adequadas, estava com necessidade de falar sobre o assunto, portanto, precisava de ajuda e orientação. Entretanto, o professor Victor considerava abstinência sexual e orientaria, no caso de ser um menino, a procurar uma mulher para acabar com o "sofrimento"; e, se fosse uma menina, perguntaria se ela já tinha vida sexual ativa, se era casada ou tinha namorado, orientando todas as "regras" e os "cuidados cabíveis"13. A atividade sexual, também, foi apontada como fator de impedimento de ampliação da perspectiva de futuro profissional e econômico das meninas, uma vez que, ao se dar prioridade a ele, surge a "gravidez precoce" que provoca o abandono escolar e repercute na trajetória social feminina. Mais uma vez, o componente da desigualdade de gênero apareceu na condução da educação sexual, pois a abstinência sexual é vista como sofrimento para o homem e para a mulher, o intercurso sexual somente pode ser pensado se acontecer dentro de um contexto de relacionamento estável, assim como os efeitos sociais de uma gravidez na adolescência são exclusivos da população feminina.

Apenas a professora Simone apresentou uma interpretação diferente e mais ampla, considerando aspectos socioculturais da situação:

\footnotetext{
${ }^{13}$ Essas regras e cuidados estão relacionados à prevenção das doenças sexualmente transmissíveis e da gravidez. 
“[...] toda música que eles estão ouvindo está falando de sexo [...] isso vai calcificando na ideia deles, então, toda sala que você entra sempre tem dois ou três alunos que não falam outra coisa [...] faltam outros assuntos, não é nem tanto por causa dos hormônios que estão à flor da pele [...] mas na própria sociedade a gente vê que falta algo que chame a atenção e de repente ainda há aquele mito hoje de que o menino bacana é aquele que pega não sei quantas por dia [...] A maioria dos ídolos da juventude de hoje tem como principal atrativo a sexualidade, sensualidade [...] você hoje não vê nenhum jovem se inspirando em fulano de tal porque ele é um estudioso, porque ele é um revolucionário, porque ele empreendeu tal luta. Quem são os heróis de hoje? Quais são as referências de hoje? Se tivesse outra alternativa, outros subsídios, se tivesse acesso a outro mundo, mas o mundo não oferece outra coisa [...] o apelo sexual hoje está em tudo, na roupa que está na vitrine, a revista que está na banca”. (Profa. Simone)

No depoimento, observamos que o cenário sociocultural no qual os/as adolescentes estão inseridos/as é determinante para a elaboração de matrizes subjetivas que mantêm os/as jovens em constante erotização; esta imersão antecede os aspectos biológicos, apresentando caráter construcionista, perdendo sua dimensão essencial. A perspectiva machista, também, é considerada ao serem indicadas as desigualdades de gênero que orientam as normas sociais da atividade sexual. As insuficientes referências pessoais, associadas à exposição frequente de artefatos midiáticos e de consumo, estimulam o apelo erótico e formam um substrato fértil para a manutenção de uma ordem discursiva no âmbito sexual.

\section{Considerações finais}

A luta pela implementação de uma educação sexual escolar, no Brasil, iniciou-se desde as primeiras décadas do século XX e culminou com a formulação de dispositivos legais que a introduziram na escola por meio dos temas transversais pelos Parâmetros Curriculares Nacionais. Entretanto, configura-se como uma temática polêmica na atualidade, pois, ainda, mantém associação com o discurso higienista e biomédico, fundamentado na necessidade de controle e disciplinamento dos corpos, justificado por um hipotético problema de saúde pública dos incrementos da incidência de gravidez na adolescência e recrudescimentos das doenças sexualmente transmissíveis, especialmente, o HIV/aids, mantendo estreita correlação com os aspectos morais.

A prática docente em educação sexual, na escola estudada, apresentou-se assimétrica entre o plano discursivo e as atitudes frente ao trabalho pedagógico desenvolvido pelas/os atrizes e atores sociais da pesquisa, no entanto, alinhada aos valores pessoais e morais em torno da sexualidade e de temas considerados mitos e tabus, como a homossexualidade e a virgindade feminina. Os possíveis motivos dessa assimetria podem estar localizados em valores pessoais e morais conservadores da ordem social hegemônica, associados a um estado de apatia ou insensibilidade à necessidade e sofrimento de outrem. Dessa forma, a transversalida- 
Quirino, G. S.; Rocha, J. B. T.

de é idealizada no âmbito dos discursos, possivelmente, por ser elemento prescrito por fundamentos legais e estruturais das instâncias que governam a educação no país, deixando a sexualidade fora, inclusive, das aulas de Ciências ou de Biologia.

Os temas sugeridos pelos/as docentes para o desempenho de uma educação sexual na atualidade ficaram concentrados em torno de mitos e tabus sexuais de base fisiopatológica e/ou epidemiológica, o que sinalizou que as/os professoras/es internalizaram as ideias biomédicas do disciplinamento dos corpos, mesmo assim, este aspecto não mostrou-se suficiente para a mudança de atitude destas/es. Ademais, o trabalho e a prática docente configuraram-se como verticalizados e descontextualizados dos aspectos históricos e socioculturais, estando centrados no ensino com pouca diversificação de recursos e estratégias didáticas e pedagógicas, o que gerava pouco impacto na clientela estudantil, manifestado pela dificuldade de concentração e atenção que os/as adolescentes apresentaram. Logo, apontamos, como possíveis causas, as interconexões existentes entre as características: do público-alvo, da subjetividade docente, das condições ambientais e materiais do trabalho, assim como o modelo epistemológico que norteia a concepção de educação.

A atitude dos/as professores/as perante a homossexualidade variou entre uma posição absolutista e liberal; estas se manifestaram por meio de brincadeiras, silenciamento e negação, referenciando a heterossexualidade normativa natural, sendo a causa apontada de ordem emocional/psicológica. Constatamos que o estudante caracterizado e conceituado de "viado" sofria mais ações discriminatórias, sendo o alvo preferencial de agressões por meio de piadas e gozações, tanto pelos seus pares quanto pelos/as docentes. $\mathrm{O}$ valor da virgindade feminina não estava referido explicitamente nos discursos, sendo a educação sexual sexista que legitima e referencia as desigualdades de gênero.

Apontamos que os constrangimentos de gênero e o reforço dos estereótipos ainda influenciam fortemente os valores e as atitudes docentes no cenário estudado. Isso reflete a sociedade brasileira como um todo, mas, especialmente, as marcas machista e patriarcal de uma cidade do interior do Estado do Ceará, no nordeste brasileiro. Esses achados mostram que o desafio de uma prática docente emancipadora, cidadã, inclusiva, e que considere as diversidades, é atual, não está consolidada, sendo meta a ser conquistada. Entendemos, também, que isso somente será possível se for acompanhada de mudança de paradigma pessoal e estrutural, com políticas públicas que estimulem ou favoreçam o rompimento com esse modelo hegemônico.

Entretanto, ainda, vivemos sob o mito da democracia sexual, o que exige do trabalho docente constante renovação, sendo preciso superar o modelo biomédico/científico na sexualidade, considerando suas dimensões histórica, social, cultural e política, cuja transversalidade das ações deve ser meta a ser alcançada nos diversos campos do saber. Nesse sentido, reconhecemos a necessidade de investimentos na formação continuada dos/as educadores/ as, pois esta pode influenciar sobremaneira o preparo técnico e emocional dos/as professores/as na efetivação e no aprofundamento da educação sexual no âmbito escolar. Uma possibilidade, que está sendo testada na referida escola e encontra-se na fase de implementação, é a utilização da pesquisa-ação como ferramenta para o desenvolvimento de metodologias participativas para discutir gênero, sexualidade e saúde reprodutiva com os/as professores/as por meio de sessões educativas. 
Prática docente em educação sexual ...

Vislumbramos, assim, que as estratégias de ensino baseadas na transmissão do saber, que privilegia a audição em detrimento da fala do/a estudante, e aquelas fundamentadas no experimento e na observação, de modo particular dentro do ensino de Ciências, têm se mostrado falhas ao tratarem do problema epistemológico do empirismo, da cultura, do entendimento generalizado, e de como as experiências particulares são influenciadas em decorrências de diferenças individuais. Portanto, consideramos que a integração dos componentes curriculares deve permitir que o mesmo objeto seja conhecido sob várias perspectivas, sem, contudo, anular a subjetividade das pessoas envolvidas no processo ensino-aprendizagem.

\section{Referências}

BORGES, Z. N. et al. Percepção de professoras de ensino médio e fundamental sobre a homofobia na escola em Santa Maria (Rio Grande do Sul, Brasil). Educar em Revista, Curitiba, n. 39, p. 21-38, jan./abr. 2011.

BRASIL. Conselho Federal de Educação. Parecer no 2.264/74. Programas de saúde: educação da saúde. Rio de Janeiro: Editex, 1974.

Lei $\mathbf{n}^{\circ}$ 5.692, de 11 de agosto de 1971. Fixa diretrizes e bases para o ensino de $1^{\circ}$ e $2^{\circ}$ graus, e dá outras providências. Brasília: Presidência da República, 1971. Disponível em: < http://www.planalto.gov.br/ccivil_03/leis/L5692impressao.htm>. Acesso em: 07 ago. 2013.

. Ministério da Educação. Secretaria de Educação Fundamental. Parâmetros curriculares nacionais: apresentação dos temas transversais: ética. 2. ed. Rio de Janeiro: DP\&A, 2000. v. 8.

- Ministério da Saúde. Secretaria de Atenção à Saúde. Cadernos de atenção básica. Brasília, 2009.

CAMARGO, A. M. F.; RIBEIRO, C. Sexualidade(s) e infância(s): a sexualidade como tema transversal. São Paulo: Moderna; Campinas: Editora da Unicamp, 2010.

CARRARA, S. et al. (Org.). Gênero e diversidade na escola: formação de professoras/es em gênero, orientação sexual e relações étnico-raciais. Rio de Janeiro: CEPESC; Brasília: SPM, 2009. $2 \mathrm{v}$.

FOUCAULT, M. Genealogia e poder. In: MACHADO, R. (Org.). Microfísica do poder. Rio de Janeiro: Graal, 2009a. p. 167-178. $2009 \mathrm{~b}$.

História da sexualidade I: a vontade de saber. 19. ed. Rio de Janeiro: Graal,

FURLANI, J. Mitos e tabus da sexualidade humana: subsídios ao trabalho de educação sexual. 2. ed. Belo Horizonte: Autêntica, 2003. 
Quirino, G. S.; Rocha, J. B. T.

HEILBORN, M. L. et al. Aproximações socioantropológicas sobre a gravidez na adolescência. Horizontes antropológicos, Porto Alegre, v. 8, n. 17, p. 13-45, 2002.

LOURO, G. L. Pedagogias da sexualidade. In: (Org.). O corpo educado: pedagogias da sexualidade. 3. ed. Belo Horizonte: Autêntica, 2010. p. 7-34.

MANO, S. M. F.; GOUVEIA, F. C; SCHALL, V. T. "Amor e sexo: mitos, verdades e fantasias": jovens avaliam potencial de material multimídia educativo em saúde. Ciência $\boldsymbol{\&}$ Educação, Bauru, v. 15, n. 3, p. 647-658, 2009.

MEYER, D. E. E. Educação em saúde na escola: transversalidade ou silenciamento? In: p. $5-17$ (Org.). Saúde e sexualidade na escola. 3. ed. Porto Alegre: Mediação, 2006.

MOSCHETA, M. S.; MCNAMEE, S.; SANTOS, J. C. Dialogue and transformation: embracing sexual diversity in the educational context. Educar em Revista, Curitiba, n. 39, p. 103-122, jan./abr., 2011.

NAKAMURA, E. O lugar do método etnográfico em pesquisas sobre saúde, doença e cuidado. In: __ _ MARTIN, D.; SANTOS, J. F. Q. (Org.). Antropologia para enfermagem. Barueri: Manole, 2009. p. 15-35.

QUIRINO, G. S.; ROCHA, J. B. T. Sexualidade e educação sexual na percepção docente. Educar em Revista, Curitiba, n. 43, p. 205-224, jan./mar., 2012.

RAGO, M. Prefácio. In: CAMARGO, A. M. F.; RIBEIRO, C. Sexualidade(s) e infância(s): a sexualidade como tema transversal. São Paulo: Moderna; Campinas: Editora da Unicamp, 2010. p. 9-12.

SANTOS, A. S. Dicionário de anglicismos e de palavras inglesas correntes em português. Rio de Janeiro: Campus: Elsevier, 2006.

SOUZA, E. R. Marcadores sociais da diferença e infância: relações de poder no contexto escolar. Cadernos Pagu, Campinas, n. 26, p. 169-199, jan./jun., 2006.

TABET, P. Fertilité naturelle, reproduction forcée. In: MATHIEU, N. C. L’arraisonnement des femmes: essays en anthropologie des sexes. Paris: Ed. Ecole des Hautes Études en Sciences Socials, 1985. p. 61-146.

VERÍSSIMO, L. F. De volta ao grunhido. O Estado de São Paulo, São Paulo, 12 out. 1997. Disponível em: <http://www.estadao.com.br/cultura/>. Acesso em: 07 ago. 2013.

WEEKS, J. O corpo e a sexualidade. In: LOURO, G. L. (Org.). O corpo educado: pedagogias da sexualidade. 3. ed. Belo Horizonte: Autêntica, 2010. p. 35-864.

Artigo recebido em 21/09/12. Aceito em 18/03/13. 